\title{
Public Perceptions of Bhutan's Approach to Sustainable Development in Practice
}

\author{
Chhewang Rinzin,' Walter J. V. Vermeulen ${ }^{2 *}$ and Pieter Glasbergen ${ }^{2}$ \\ ${ }^{1}$ Royal Institute of Management, Semtokha, Thimphu, Bhutan \\ ${ }^{2}$ Utrecht University, The Netherlands
}

\begin{abstract}
This paper focuses on the practical approach to sustainable development in Bhutan and specifically on public views on and experiences with the implementation of this strategy. Bhutan's development goal is 'gross national happiness'. The strategy it has adopted to achieve this goal is known as the 'middle path strategy', which essentially addresses four sources ('pillars') of gross national happiness: economic development, ecological preservation, cultural preservation and good governance, without giving greater emphasis to any one pillar over the others. The paper is based on a survey conducted in 10 districts of Bhutan. Standard pre-designed questionnaires were used for interviews with representatives of three main groups in society: the state, civil society and the market.

The results of this survey, the first of its kind to be carried out in the country, revealed that there is general agreement with the substance of the development strategy, although not everyone is fully aware of its scope and implications. A remarkable outcome of the survey, and one that contrasts with happiness studies conducted elsewhere in the world, was the high score for happiness in a country whose gross domestic product is so small. However, people do feel uncertain and the chosen development path is still fragile. Copyright (C) 2006 John Wiley \& Sons, Ltd and ERP Environment.
\end{abstract}

Received 11 July 2005; revised 25 September 2005; accepted 19 October 2005

Keywords: government policy; implementation; public opinion; happiness; developing countries 


\section{Introduction}

- $N$ THIS PAPER WE DISCUSS THE DIFFUSION OF THE CONCEPT OF SUSTAINABLE DEVELOPMENT IN Bhutanese society. As a small land-locked country (Figure I), Bhutan is experiencing various farreaching societal transitions. It is changing from a rural society, based on subsistence farming, to a society with growing service and industrial sectors, which increasingly relies on exports of hydroenergy and income from tourism for economic growth. The country is also witnessing the first cultural impacts of a slow but irreversible transition due to its opening up to globalization. Meanwhile, the government system is changing from a closed centralized monarchy into a democratic constitutional monarchy with a decentralized system of governance. Bhutan occupies a special position in the international arena by explicitly adopting sustainable development as the central objective of its development.

The Kingdom of Bhutan is situated in the Eastern Himalayas, between mainland China to the north and India to the south. It covers a total area of 38398 square kilometres and has an estimated population of 752700 . In 1998, the King of Bhutan stepped down as the head of government, assigning that function to a prime minister. The prime minister is assisted by cabinet ministers, who are elected by the members of the National Assembly for a term of five years. Each minister serves as prime minister for a period of one year in rotation. The National Assembly passes legislation by a simple majority vote.

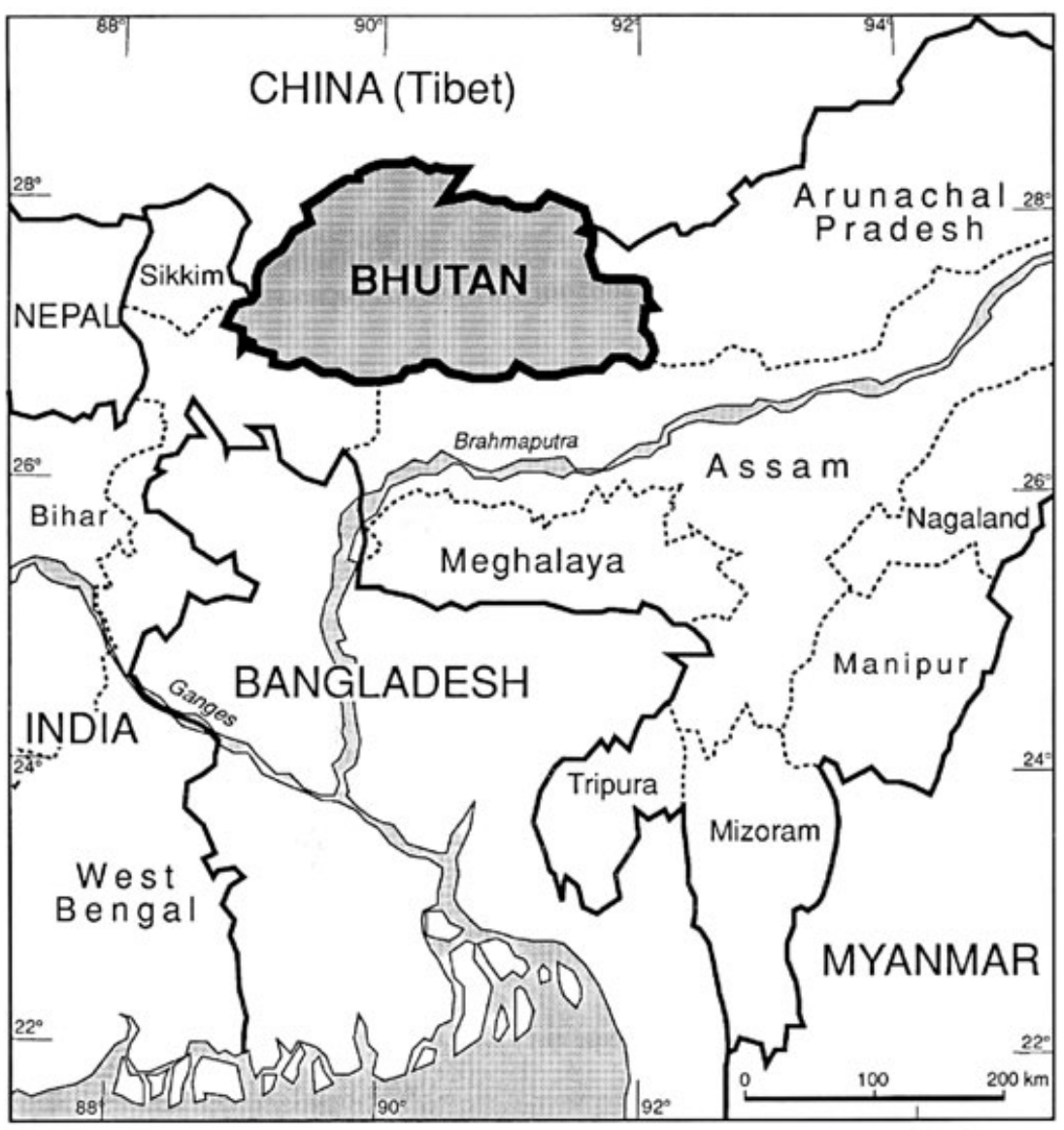

Figure 1. Bhutan and its neighbouring countries 
It has 150 members representing the state, the monk bodies and the people. In the near future a new constitution will be adopted to strengthen the democratic constitutional monarchy (RGoB, 2005).

Bhutan has exceptionally diverse flora and fauna due to the country's great range of altitudinal zones and varied climatic conditions. Forests cover $72 \%$ of the country, and the government is determined to conserve this natural wealth and has a national policy to maintain at least $60 \%$ of the land under forest cover for all time (RGoB, 2002). The national economy is dependent on the traditional sectors, agriculture, animal husbandry and forestry. Electricity generated from hydropower constitutes a major export product to India. According to the Energy Master Plan, the country's hydropower potential is estimated at over $30000 \mathrm{MW}$. The installed capacity of $457 \mathrm{MW}$ accounts for about II\% of the gross domestic product (GDP) and provides the government with about $45 \%$ of its total revenues (Asian Development Bank, 2005). Tourism is another important growth sector in Bhutan, contributing a substantial amount of hard currency.

The overall environmental impact of the Bhutanese way of life is still very small (van Vuuren and Smeets, 2000). The government intends to minimize any deterioration that may be caused by future economic growth.

In this paper we will first briefly discuss the background to the Bhutanese development path, which is closely linked to Buddhist economic principles. In the next section we will then present the research methods applied in our survey of 775 respondents throughout the country. The results of this survey will be discussed in the fourth to sixth sections, and in the seventh section we will reflect upon these findings.

\section{Bhutan's Development Policy: the Middle Path Strategy Towards Gross National Happiness}

Being a Buddhist country, Bhutan's development policy is primarily influenced by Mahayana Buddhism. Buddhist economists, like Payutto, Phrabhavanaviriyakhun, Schumacher and others, argue that in a Buddhist society the lifestyle is strongly influenced by the Buddhist 'way of life', which is based on the principles of the Noble Eightfold Path. ${ }^{\text {I }}$ Schumacher argues that 'Right Livelihood', the fifth path, touches upon economic aspects of Buddhist life and forms the basis of economic principles (Schumacher, I966). It embraces the relationship between three interconnected aspects of human existence: human beings, society and the natural environment. Maintaining the balance among these enhances the quality of life for the individual, for society and for the environment (Payutto, I988; Phrabhavanaviriyakhun, 200I). Welford argues that this Buddhist principle could even be extended to enhance sustainability in western economic practices (Welford, 2000). In essence, the Buddhist perspective is that development is a holistic process, which should be directed to meeting the material, social and spiritual needs of human beings (Wickramasinge, 2000).

This approach can be seen in the national policies of Bhutan and its commitment to sustainable development, which is defined as a process 'to raise the material well-being of all citizens and meet their spiritual aspirations, without impoverishing our children and grandchildren' (RGoB, I990). Sustainable development has a special meaning and appeal in Bhutanese society, since it supports harmonious coexistence with the natural system, which is consistent with the common Buddhist beliefs. This relationship is manifested in peoples' beliefs that high mountains and deep ravines, ancient trees and rocks are the abode of spirits, gods and demons. Disturbing these elements would enrage these spirits and

\footnotetext{
${ }^{\text {I }}$ According to Buddhism, the path of liberation, the Noble Eightfold Path, is a graduated process leading from the mundane to the transcendental. It encompasses Right Understanding, Right Thought, Right Speech, Right Action, Right Livelihood, Right Mindfulness and Right Concentration.
} 
bring ill luck, sickness and death to families. By contrast, appeasing these spirits would be rewarded with luck, peace and prosperity (Ura, 2004).

In line with these views, Bhutan's development strategy is guided by the philosophy of 'gross national happiness'. This concept expresses a preference for happiness over accumulation of material wealth and the development path therefore rests on the four so-called pillars of development:

- sustainable and equitable economic development;

- ecological preservation;

- cultural preservation;

- good governance.

The development philosophy therefore states that the country should pursue a balanced or 'middle way' development strategy. It is based on the belief that moderate consumption leads to the realization of true well-being or quality of life. Or, as the old Bhutanese proverb puts it, it is better to have milk and cheese many times than beef just once', implying that short-term gains must not override long-term benefits (NEC, I998). In this sense, the middle path implies avoiding extremes or seeking moderation in order to achieve the overall goals, thus causing less ecological impact.

As in other developing nations, there is urgency in the drive to achieve and sustain economic progress. This is demonstrated by the framework of the middle path strategy model (Figure 2), which encapsulates the four pillars of gross national happiness. The government identified three avenues of development for triggering growth: hydropower development based on integrated watershed management; forest management and agriculture development based on sustainable practices and industrial development based on clean production technology (NEC, I998).

The middle path strategy was formulated within a traditional governmental context of a closed, enlightened and centralized monarchy. With the prevalence of the uniform Buddhist belief system in the country, it was assumed that the people of Bhutan would broadly support this route. It is of the

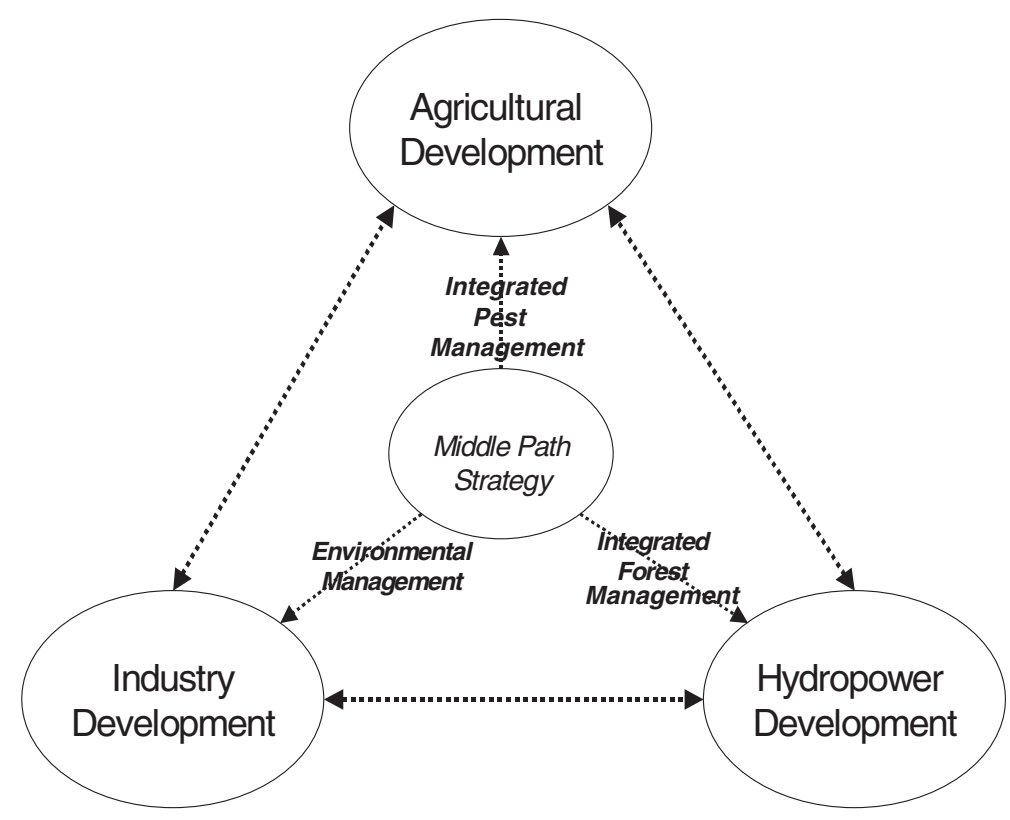

Figure 2. Web of dependencies within the prudent framework of economic development, ecological and cultural preservation and good governance 
utmost importance that actors within the sphere of the state, the market and civil society think and act in the spirit of this middle path strategy (Driessen and Glasbergen, 2002).

However, this assumed broad societal commitment has never been investigated and the growing economic and cultural impact of globalization poses a serious challenge to it. The concept of gross national happiness also provoked international debate about 'what is happiness?' and 'how can one measure and operationalize it?' and 'whether measurement is advisable' (Dorji, unpublished; Mancall, 2004; Tashi, 2004; Hirata, 2003; Tashi, Prakke, and Chetri, I999; Thinley, I999; Sharrock, I999; Stehlik, I999). In international research these questions have been discussed extensively and approached empirically even in a cross-national context. According to sociologists such as Inglehart and Veenhoven, human happiness shows a strong linkage with economic development. As a country moves from a subsistence-level economy to an advanced industrial society, people tend to be happier and more satisfied with their lives as a whole. However, as they move beyond a given threshold people begin to emphasize quality of life concerns such as environmental protection, lifestyle issues and non-materialistic values (Inglehart and Klingemann, 1996; Veenhoven, I999). Remarkably, participants in this debate did not approach the question empirically and no one has previously asked the people themselves on this scale and depth.

Therefore, in this study, we intend to fill this knowledge gap by studying the people's perceptions and understanding of the four pillars of gross national happiness (GNH), thus contributing to theories on individual and societal happiness.

\section{Research Methods}

Data collection for this paper was carried out in June and July 2004. The information collected mainly concerns public perceptions and the implications of the four pillars of gross national happiness, the middle path strategy and individual happiness. Both primary sources and secondary sources were used. Primary data was collected by conducting structured interviews, as well as open interviews with government officials at the ministries and in the districts. As secondary sources we used published and unpublished government reports.

The interviews covered to out of the 20 districts in Bhutan. The geographical locations of interviews were selected on the basis of three main criteria: the ecological zone (identified as those districts that fall either in the conservation area or in the zones connecting various conservation areas), the level of development and the presence or absence of the influence of tourism (see Figure 3). The respondents belong to each of the three major societal groups: the civil society (consisting of farmers, NGOs and the religious community), the market (represented by the business community) and the state (represented by civil servants, including teachers). In the selected districts, the representatives of civil society and the market were randomly selected. A total of 775 respondents were interviewed, of whom $4 \mathrm{I} \%$ represented civil society, $20 \%$ represented the market and $39 \%$ were state representatives.

Data were collected by using pre-designed and structured questionnaires. Post-graduate trainees from the Development Management Programme of the Royal Institute of Management conducted the interviews as part of their academic requirement. They were trained in research methods, interview techniques and report writing. Before the actual interviews were conducted, the questionnaires were pre-tested and reviewed in light of comments from the respondents.

The data were processed using SPSS software. We included questions about the respondents' perception and feelings about economic development, conservation of nature and culture, decentralization policies and happiness. In our analysis we checked for significant variances in the answers of the three societal groups and of different regional groups. We analysed these differences by using basic descrip- 


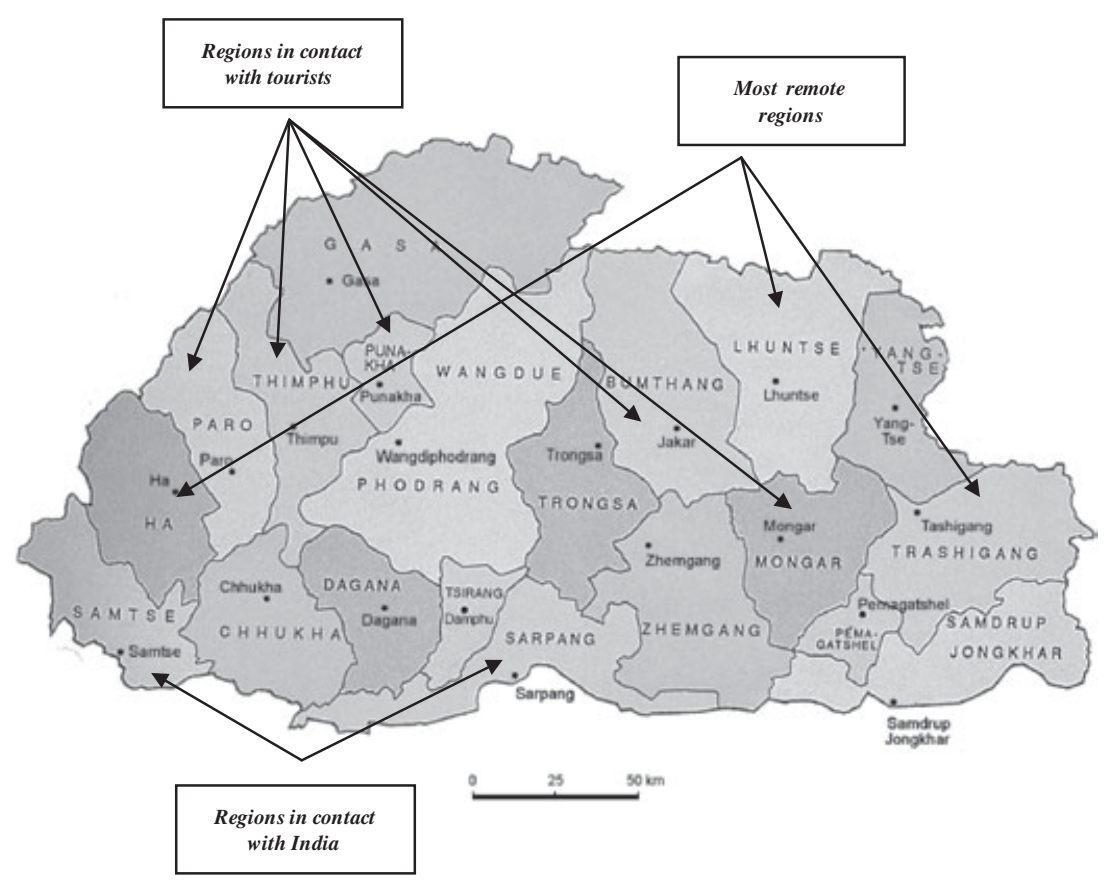

Figure 3. Regions studied in Bhutan

tive statistical tools, i.e. frequency and cross tabulations. Differences between societal groups or regional groups were tested for significance applying the chi square and rejecting differences where $p>0.05$.

\section{Gross National Happiness: How Do People Perceive and Value the Four Pillars?}

As discussed above, the concept of gross national happiness has been translated into four pillars of development. This section presents the results of the research on these four pillars.

\section{Sustainable and Equitable Economic Development: the First Pillar of GNH}

The government of Bhutan will complete its ninth five-year socio-economic development programme in June 2007 . We analysed the opinions of the people on the progress achieved so far.

In general, the Bhutanese are positive about the economic development achieved in the last decade. The vast majority of the people want the economy to grow. At the same time, people have enjoyed improvements in health $(87 \%)$, living conditions (65\%), communication (40\%) and education (3I\%), which indicates that basic needs for general well-being are being met. Responses were mixed as regards the extent to which the benefits of development have been shared. Table I shows that only I9\% of the respondents felt that the benefits of economic development were equitably shared to a 'large extent', while a large majority $(67 \%)$ were indecisive, saying 'more or less'. More of the respondents representing civil society tended to think that the benefits of development had been shared equitably to 'a large extent' $(26 \%)$ than in the other groups.

We also found that respondents from districts bordering on India said that benefits had been equitably shared to 'a large extent' more often than in the other two regional categories.

How do individuals value economic well-being, environmental preservation, cultural and spiritual well-being in their own lives? From Table 2 we see that on average economic, cultural and spiritual well- 


\begin{tabular}{lccc}
\hline Societal group & $\begin{array}{c}\text { Large extent } \\
(\%)\end{array}$ & $\begin{array}{c}\text { More or less } \\
(\%)\end{array}$ & $\begin{array}{c}\text { Not at all } \\
(\%)\end{array}$ \\
\hline State & 12.4 & 75.3 & 12.4 \\
Civil society & 25.9 & 58.3 & 15.9 \\
Market & 18.1 & 67.1 & 14.8 \\
Total & 19.1 & 66.6 & 14.3 \\
\hline
\end{tabular}

Table 1. Opinions of citizens about the equitable sharing of benefits of economic development $(n=775)$ Chi-square $=22.9, p=0.00$.

\begin{tabular}{lcccc}
\hline & $\begin{array}{c}\text { State } \\
\%\end{array}$ & $\begin{array}{c}\text { Civil } \\
\text { Society } \%\end{array}$ & $\begin{array}{c}\text { Market } \\
\%\end{array}$ & $\begin{array}{c}\text { Average total } \\
\%\end{array}$ \\
\hline Economic well-being & 46.5 & 32.1 & 56.1 & 42.5 \\
Environmental preservation & 26.5 & 24.6 & 14.8 & 23.5 \\
Cultural and spiritual well-being & 28.1 & 45.2 & 31.0 & 35.7 \\
Total & 100 & 100 & 100 & 100 \\
\hline
\end{tabular}

Table 2. Ranking of 'economic well-being', 'environmental preservation' and 'cultural and spiritual well-being' as the most important value to individual lives $(n=775)$

being are regarded as more important than environmental conservation. We also see that respondents in the state and market groups ranked economic well-being as most important (47 and $56 \%$ respectively) more often than respondents from the civil society, who tended to favour spiritual well-being (45\%). There were no significant differences of opinion in the responses according to the remoteness of a region.

Respondents gave various reasons for their choice of values as shown in Table 2 . The reasons most often cited were 'without economic development environmental and culture preservation is not possible' (I7\%), culture gives a sense of 'national identity' (8\%) and the environment provides a 'basic necessity' $(6 \%)$, indicating that environment and economy are perceived to be inextricably linked.

Public opinion on the socio-economic pillar shows that people have experienced fairly balanced economic development in the past and that the benefits have been more or less equitably distributed amongst citizens, indicating a fair distribution of wealth. However, due to topographical difficulties some remote regions enjoyed less progress, suggesting that the remote districts have been less effectively addressed by development programmes than other districts in the country. However, it is noticeable that people living near the Indian border experienced less hardship. As a result, they appear to be more satisfied with the level of development than people living in the north. This may be explained by the fact that goods and services are more readily available near the border, the people are living in a warmer climate and the land is more fertile.

\section{Conservation of the Environment: the Second Pillar of GNH}

Buddhism emphasizes preserving nature and the sanctity of life. The importance of protecting nature has permeated Bhutanese consciousness and has become integral to the Bhutanese way of life and value system (RGoB, I996, I999). All policy papers of the Bhutanese government therefore enunciate this philosophy. In this section we present the analysis of public feelings towards the importance of environmental preservation. 


\begin{tabular}{lc}
\hline Perceived benefits: maintaining natural resources & $\%$ \\
\hline Conservation of biodiversity & 52.9 \\
Prevention of natural disasters & 51.7 \\
Maintain clean environment & 44.0 \\
Perceived benefits: socio-economic progress & $\%$ \\
Source of income/sustainable development & 70.9 \\
\hline
\end{tabular}

Table 3. Perceived benefits of preserving the environment (open ended question, $n=775$ )

\begin{tabular}{lccc}
\hline Societal groups & Liberal & Stringent & Just right \\
\hline State & 11.2 & 23.1 & 65.8 \\
Civil society & 4.1 & 35.5 & 60.4 \\
Market & 13.7 & 25.5 & 60.8 \\
Total & 8.6 & 28.4 & 61.8 \\
\hline
\end{tabular}

Table 4. Assessment of environment policy according to societal groups $(\%, n=775)$

Chi-square $=24.04, p=0.000$.

The research shows that an overwhelming majority (99\%) of the respondents rated environmental conservation as very important. This rating is very closely related to the perceived benefits emanating from conservation, as shown by the results of the survey shown in Table 3. Two main benefits were highlighted. A large majority of the respondents (7I\%) believe that the environment provides the basis for socio-economic progress, while a smaller majority also believes that conservation also helps to preserve natural resources.

Asked about their familiarity with the government's environmental policy, $75 \%$ of the respondents said they were aware of the policy and $95 \%$ believed environmental policy would help protect the environment. When asked to rate the 'stringency' of the environmental policy (Table 4), 62\% of the respondents said the policy was 'just right', while $28 \%$ said it was 'stringent'. Comparing the views of the different societal groups on this point, a larger proportion of people from civil society $(36 \%)$ said the policy was stringent than in the other two societal groups. Respondents from regions with more frequent contact with tourists also considered the environmental policy to be 'stringent' (32\%) more often than respondents in districts bordering on India (I9\%) and remote regions (29\%).

The survey results indicate that there is overwhelming support for the conservation efforts of the government. People show awareness of the benefits of environmental preservation and most of them have a clear motivation for this. This indicates that consistent efforts made by government and public agencies like the National Environment Secretariat, the Nature Conservation Division and the NGOs to educate people on the importance of preserving Bhutan's fragile mountainous ecosystem are bearing fruit. The overall environmental policy appears to be just right. However, a relatively large number of people from civil society say it is stringent, indicating that their daily lives are impacted by the policy. This reality is reflected in the difficulties faced by farmers with the depredations of wildlife on crops as well as on domestic livestock.

\section{Preservation and Promotion of Culture: the Third Pillar of GNH}

The policy objective of the Bhutanese government also emphasizes preservation and promotion of cultural and traditional values deemed pertinent for the country's distinct identity as a nation state (RGoB, 
The Bhutanese culture is based on customary rules, norms, indigenous knowledge systems and institutions, in addition to a rich religious heritage based on a unique blend of Mahayana and Vajrayana Buddhism. It includes a code of conduct known as driglam namzha, which is designed to carve out a distinct Bhutanese identity. In addition to promoting national dress (the gho for men and the kira for women), driglam namzhag is built upon a strict observance of vows (tha-damtshig) that emphasise strong kinship loyalty, community-oriented behaviour, hospitality to guests, respect for one's parents, elders and superiors and mutual cooperation between rulers and ruled, parents and children, and teachers and students.

Box 1. Historical roots of Bhutanese cultural heritage and its value system

Source: NEC, 1998.

I999). Preserving traditions is essential for the functioning of a harmonious and progressive society (Box I) and for achieving gross national happiness.

The survey results show that a vast majority (99\%) of the Bhutanese people consider culture to be 'very important' and fully support its preservation. The reasons given were generally linked to national identity (90\%), security (52\%), income generation through tourism activities (I5\%) and conservation of a way of life (I4\%).

When asked about the importance of culture in sustainable development in general, a large majority of the respondents (97\%) said it is important for sustainable development. Analysis of the views of the different societal groups as shown in Table 5 reveals similar results to those discussed above. However, more people from civil society stress that culture helps to preserve indigenous knowledge (23\%), while state representatives more often say that it helps to 'maintain the value system' and stress 'respect as unifying force' (30\%).

The data show that respondents in remote districts tended to put more emphasis on identity, whereas the people in contact with tourists stress that culture should be preserved as a way of life.

Public opinion on the cultural pillar shows that there is a common understanding amongst Bhutanese people that culture is very important, as it serves to identify Bhutan as a nation state. Most people in the remote districts support cultural preservation, saying that it plays a symbolic role in Bhutanese society, since it enables the people to differentiate themselves as a community from the rest of the world. This feeling reflects a sense of insecurity in the people due to the country's geopolitical position in South Asia. Culture is also seen as unifying force, a bond between people, indicating that one nation with one culture leads to a harmonious society.

\section{Good Governance: the Fourth Pillar of GNH}

Good governance has been promoted with the dual objectives of democratization and development, and ultimately the goal of local self-governance. It is also recognized that bringing the decision-making

\begin{tabular}{lccc}
\hline Societal groups & $\begin{array}{c}\text { Preserve national } \\
\text { identity (\%) }\end{array}$ & $\begin{array}{c}\text { Respect as unifying } \\
\text { force (\%) }\end{array}$ & $\begin{array}{c}\text { Preserve indigenous } \\
\text { knowledge (\%) }\end{array}$ \\
\hline State & 55.3 & 30.0 & 14.7 \\
Civil society & 58.8 & 18.8 & 22.5 \\
Market & 68.0 & 15.7 & 16.3 \\
Average total & 59.3 & 22.5 & 18.0 \\
\hline
\end{tabular}

Table 5. Importance of cultural preservation for sustainable development $(\%, n=775)$

Chi-square $=20.84, p=0.000$. 


\begin{tabular}{lcc}
\hline Societal groups & $\begin{array}{c}\text { Decision directed by } \\
\text { chairman }(16 \%, n=126)\end{array}$ & $\begin{array}{c}\text { Decision directed by central } \\
\text { government }(19 \%, n=148)\end{array}$ \\
\hline State & 54.4 & 35.7 \\
Civil society & 25.6 & 44.7 \\
Market & 20.0 & 19.6 \\
Total & 100 & 100 \\
\hline
\end{tabular}

Table 6. Societal views on how development decisions were made at the district level Chi-square $=20.43, p=0.000$ (chairman); chi-square $=16.54, p=0.002$ (central government).

process closer to local communities is seen as a primary step in the operationalization of the vision of gross national happiness $(\mathrm{RGoB}, 2003)$. As this policy of decentralization and public participation has been central to Bhutan's development process, we will focus on this aspect of good governance.

A programme for local governance started in the I980s with the objective of engaging local communities in development activities. The formal organizational structure and procedures, including legal frameworks for decentralization, have evolved over the last three decades. The establishment of development committees (DYTs and GYTs) ${ }^{2}$ has involved the people in political, social and economic decision-making and enhanced their ability to set their own development priorities. This political process culminated in the enactment of the DYT and GYT Acts and the transfer of the chairmanship of the DYT to an elected public representative in 2002. This chair was formerly held by the state-appointed district administrator. Thus the new acts gave more power and legitimacy to this important development committee.

This study explored public opinion about the decentralization process. The survey results show a high level of support and appreciation for the government's decentralization effort, which is rated as 'good' (96\%). The reasons given by the respondents to justify this were that 'it promotes people's participation and empowers people' (55\%) and 'it promotes balanced development' (23\%). A small minority (6\%) also said 'it enables them to have their voices heard in the National Assembly'.

In relation to the implementation of the decentralization programme, we asked the respondents for their opinion on how local decisions are made and communicated to the central government. The survey results show that a majority $(59 \%)$ of the respondents are of the view that decisions are made based on need and on a participatory basis, while I9\% responded that the decisions are directed by the central government and I6\% feel that the DYT chairman directs the decisions. This outcome suggests that decentralization is taking effect in practice and people in the regions recognize the virtues of the new system of local governance. But the views expressed by the societal groups on whether decisions are directed by the chairman and the central government differ (Table 6). The respondents representing the state felt that the chairman of the DYT directs decisions (54\%), while respondents from the civil society felt that the central government directs decisions (45\%); the market representatives assumed a neutral position. The opinions expressed in the various regions also differ. Respondents from remote regions more often felt that the central government directed the decisions (30\%) than respondents in regions in contact with tourists ( $17 \%$ ) and regions located along the Indian border (13\%).

As regards communicating local decisions to the central government, $33 \%$ said these are fully communicated, while $65 \%$ maintained they are only partially reported. Broken down by societal group, the

${ }^{2}$ DYT and GYT are Dzongkha (official spoken language) acronyms for District Yargay Tshochung and Geog Yargay Tshogchung. DYTs were established in I98I. GYTs were first introduced in I99I, in order to promote further decentralization. DYT and GYT Acts were passed in 2002 during the 8Ist session of the National Assembly. 


\begin{tabular}{lccc}
\hline Societal groups & Fully & Partially & Not at all \\
\hline State & 24.5 & 73.8 & 1.7 \\
Civil society & 42.9 & 55.8 & 1.3 \\
Market & 30.7 & 66.7 & 2.6 \\
Total & 33.4 & 64.9 & 1.7 \\
\hline
\end{tabular}

Table 7. Views of societal groups on communication of local decisions to the central government Chi-square $=24.69, p=0.000$.

\begin{tabular}{lcc}
\hline Societal groups & Yes (\%) & No (\%) \\
\hline State & 63.8 & 36.2 \\
Civil society & 35.9 & 64.1 \\
Market & 46.8 & 53.2 \\
Average & 48.0 & 52.0 \\
\hline
\end{tabular}

Table 8. Knowledge and understanding of the middle path strategy Chi-square $=47.79, p=0.000$.

results reveal that more respondents from the state group felt the decisions were partially communicated $(74 \%)$, while relatively more people from civil society $(43 \%)$ said that decisions are fully communicated (Table 7).

Looking at the perceived benefits and risks of decentralization, most often perceived benefits are 'people's participation in development programmes' (50\%), 'bringing need-based development' (38\%) and 'opportunity to elect your own leader' (30\%). The most frequently cited risks include 'risk of corruption' (58\%), 'lack of capacity' (38\%) and 'inequitable leadership' (28\%), while a small group also said decentralization could lead to 'unbalanced development due to improper planning and understanding of the decentralization policy' (II\%).

The analysis of people's feelings indicates an eagerness to be personally involved in development activities. Significant numbers of respondents observed that local decisions are still directed by central government, suggesting that people feel they are not given total freedom to make their own local decisions. The survey also revealed that there is a concern that decisions are only partially communicated to the central government. This indicates two things. First, it demonstrates the level of awareness of decentralized governance being created by the government. Second, it shows the dilemmas the bureaucracy is facing in transforming the traditional 'top-down' system. At the same time, it appears that people are also apprehensive about decentralization because of the risk of corruption and the absence of sufficient local capacity, which could compromise development work.

\section{The Middle Path Strategy as an Instrument for GNH}

Achieving balanced development by making a conscious choice between economic growth and conservation is the primary concern of the middle path strategy. In this section we look more closely at public perceptions and support for this development strategy.

First, we asked whether people knew about the middle path strategy. The results shown in Table 8 reveal that $52 \%$ of the respondents said they had no knowledge of the development strategy, but there was greater awareness among the respondents representing the state $(64 \%)$. 


\begin{tabular}{lr}
\hline Opportunities & $\%$ \\
\hline Balanced development & 63.2 \\
Prove a model development for others & 6.1 \\
Improve economic welfare through increased sources of income & 5.7 \\
Achieve gross national happiness & 4.5 \\
Challenges & 31.6 \\
No risk & 28.8 \\
Slow development due to under-utilization of resources and lack of & \\
cooperation from local people & 7.8 \\
Misinterpretation & \\
\hline
\end{tabular}

Table 9. Opportunities and challenges foreseen in the implementation of the middle path strategy (open question, $n=775$ )

Many of those who were aware of the middle path strategy described it as an opportunity to achieve sustainable development by balancing spiritual and material needs (63\%). A large group (32\%) also said the middle path strategy would not bring serious risks (Table 9). However, another group suggested there were risks, with $29 \%$ of the respondents saying that slower development due to the underutilization of resources could be a major risk.

The overall results show that fewer than half of the people interviewed appeared to understand the middle path as a development strategy (48\%). Interestingly, a large number of state representatives (36\%) also said they were not aware of this strategy. This anomaly demonstrates the need for more campaigns to increase awareness of the importance of the strategy. However, in general, people seem to agree with the philosophy, the spirit and the intent of the strategy. The survey results indicate that $88 \%$ consider the middle path strategy to be the best strategy for Bhutan. This view suggests that people care for and strive to safeguard both the environment and culture in the drive towards achieving happiness through balanced development. However, some concerns were raised about the risk of a slowdown in development due to under-utilization of resources, misinterpretation of the concept, difficulty in monitoring and lack of awareness. This indicates that people desire economic growth and a slowdown would disappoint the aspirations of the general public.

\section{Perception of Gross National Happiness}

In this section we discuss the perception of happiness among the Bhutanese people and assess the level of individual and societal happiness. Generally speaking, Bhutanese people perceive happiness as encompassing four aspects: economic, socio-cultural, environmental and political. People tend to attach varying degrees of importance to each of these aspects. In response to an open question on what in their view happiness is, our survey shows that $69 \%$ consider peace and security to be important, followed by material well-being and self-sufficiency $(55 \%)$ and spiritual well-being $(27 \%)$. The ecological aspect was mentioned relatively less often $(7 \%)$ than the other three aspects.

Based on the general perceptions mentioned above, the respondents were asked to rank the presumed elements of happiness in order of importance at the national level. National security was accorded a high priority: $72 \%$ ranked it as 'very important', while the smallest proportion of respondents regarded 


\begin{tabular}{lcccc}
\hline Elements of happiness & $\begin{array}{c}\text { Very important } \\
(\%)\end{array}$ & $\begin{array}{c}\text { More important } \\
(\%)\end{array}$ & $\begin{array}{c}\text { Important } \\
(\%)\end{array}$ & $\begin{array}{c}\text { Less important } \\
(\%)\end{array}$ \\
\hline Spiritual well-being & 43.2 & 32.6 & 18.1 & 5.7 \\
Material wealth & 19.2 & 41.3 & 29.3 & 9.1 \\
Secure social life & 41.3 & 39.7 & 14.5 & 3.9 \\
Maintain natural environment & 37.3 & 41.3 & 16.5 & 4.1 \\
Preservation of cultural heritage & 48.5 & 32.6 & 14.5 & 9.1 \\
National security & 72.3 & 18.6 & 6.3 & 2.4 \\
\hline
\end{tabular}

Table 10. Importance attached to six elements constituting happiness at the national level $(n=775)$

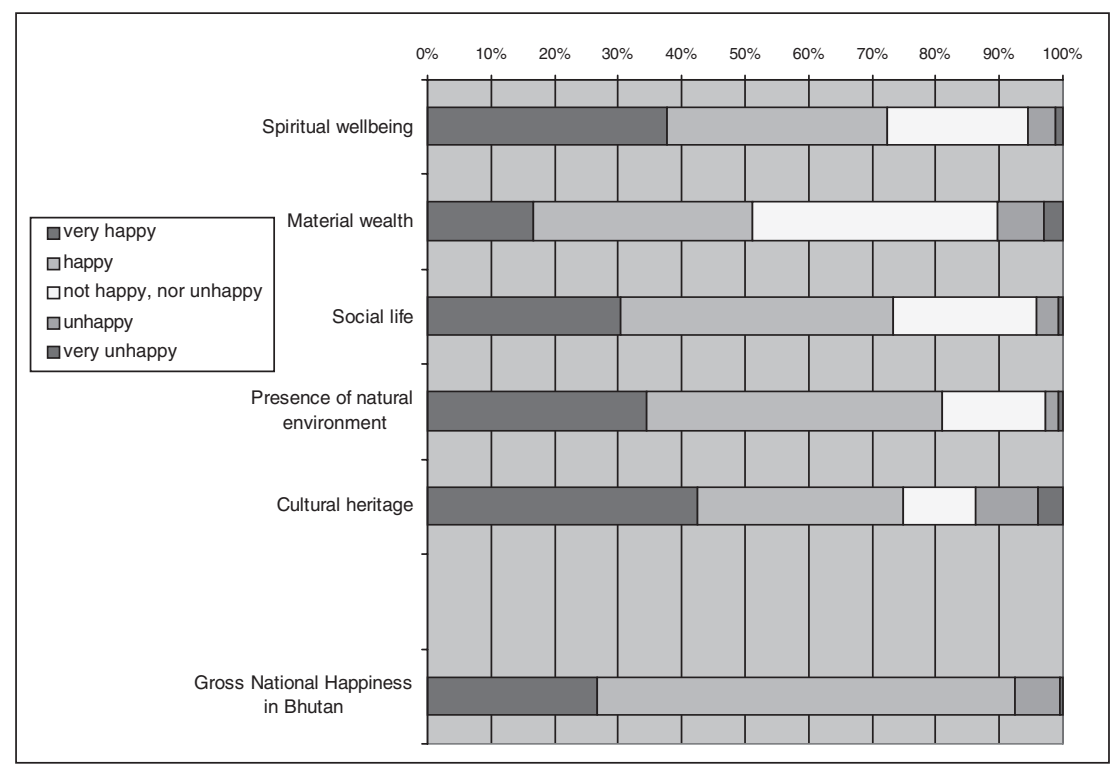

Figure 4. Level of happiness with respect to various aspects $(n=772)$

material wealth as 'very important' (э9\%). However, material wealth and maintaining the natural environment were ranked as 'more important' by a relatively large proportion of respondents (4I\%) (Table IO).

Figure 4 shows the level of happiness at the individual level in Bhutanese society. The results show that the largest number of people feel 'very happy' (42\%) with respect to cultural heritage, followed spiritual well-being (38\% 'very happy'). The next most important sources of happiness are the natural environment $(35 \%)$ and a secure social life $(30 \%)$. The level of individual happiness related to material wealth is the lowest (I7\%) of all the elements.

Figure 4 also shows the level of gross national happiness in Bhutan at this moment, according to the respondents. The vast majority rank the level of GNH as 'very happy' (27\%) and 'happy' (66\%). At the same time, $7 \%$ rank the level of GNH as 'unhappy' and a small minority (0.5\%) ranks the level as 'very 


\begin{tabular}{lcccc}
\hline Societal groups & Very happy & Happy & Unhappy & Very unhappy \\
\hline State & 21.3 & 68.9 & 9.8 & 0.0 \\
Civil society & 33.0 & 62.3 & 4.0 & 0.6 \\
Market & 23.2 & 67.1 & 8.4 & 1.3 \\
Total & 26.6 & 65.5 & 7.1 & 0.5 \\
\hline
\end{tabular}

Table 11. Level of gross national happiness in Bhutan, according to societal groups $(n=775)$ Chi-square $=20.83, \mathrm{df}=6, p=0.002$.

unhappy'. Comparing societal groups, we observe that the level of 'unhappiness' (Iо\%) is higher and the level of 'very happy' (2I\%) is lower among state representatives than among respondents in market and civil society groups (Table II).

From the above analysis we can say that in Bhutan happiness rests upon four domains of the development ethos: achieving economic self-sufficiency, national security and maintaining ecological and spiritual well-being. These elements were consistently echoed even at the level of individual happiness. As a result, people's perception of happiness consists of a combination of feeling secure, acquiring basic needs and the presence of spiritual well-being. People tend to make a link to environmental quality less often, but the question on individual happiness shows that the natural environment also is seen as the most important source of happiness, indicating that people still live close to the natural environment. The results for the three societal groups show that the state and the market representatives perceive higher levels of gross national unhappiness compared with civil society members. This tendency may very well arise from the fact that the first two groups include more educated respondents and they are more exposed to the outside world.

\section{Conclusion}

The development philosophy of Bhutan is guided by the concept of maximizing gross national happiness rather than simply maximizing gross domestic product. Promoting happiness as the development objective places the individual at the heart of all development efforts and recognizes that the individual has material, spiritual and emotional needs. To achieve this goal, the National Environment Strategy, called the 'middle path strategy', has been implemented. The strategic intention and the direction of this strategy is to lead the country towards a more sustainable future by taking a different, Buddhisminspired route to development: the middle path. Based on our findings we can state that this unique national development strategy rests on the beliefs of ordinary citizens. We have shown that civil servants and people from civil society groups and the market fully support the spirit of the development strategy, although not always with a full understanding of the official concept.

In general, people in Bhutan are aware of the importance of the four pillars of gross national happiness: sustainable and equitable economic development, conservation of the environment, preservation and promotion of culture and good governance. This supports the validity of the development philosophy. Our study shows the following for each of these pillars.

- The past results of development appear to have been equitably shared amongst the citizens, except in some remote districts, which enjoy fewer benefits. Districts closer to the Indian border were especially positive about the equitable sharing of benefits. 
- There is full support for environmental preservation (99\%) and there is a great awareness of environmental policy (75\%). Most people are aware of the consequences of and reasons for government policy to protect the environment. One reason for such a high level of awareness could be the continuous efforts of the government to educate people on the importance of preserving the environment, explaining that collective efforts are essential for survival in a fragile Himalayan ecosystem. Our data show that these policies are effective in influencing the thinking of individuals throughout the country.

- Culture is considered very important and there is overwhelming support for its preservation (99\%). People believe that culture serves to identify Bhutan as a nation state (90\%) and that it provides security $(52 \%)$. This result can be explained by assuming that the people are aware of the strategic location that Bhutan occupies and of obvious threats to its identity and security.

- There is substantial support for the government's decentralization programme (96\%). People report that it facilitates public participation (55\%) and brings about need-based development. At the same time, people are also apprehensive about the possible risks of decentralization, saying it could encourage corruption at the local level (58\%) and that there is a lack of local capacity. One reason could be that in recent years there have been irregularities during elections at district and local levels and the people probably feel this could grow as more power is decentralized.

Looking at the middle path strategy, the results show that fewer than half of the people interviewed were aware of what the strategy represents. This ignorance is greatest amongst the civil society group $(64 \%)$, followed by market (53\%) and state $(36 \%)$. These findings suggest that the strategy needs to be explained so that people know the intention of government policy.

Creating gross national happiness is the main aim of public policy in Bhutan. Our study shows what the people themselves actually perceive as being essential for happiness. In the Bhutanese society, happiness does not require material wealth alone, but a balance between economic development and ecological and cultural preservation, while spiritual values are considered equally important for the stability of the state. Our findings show that at the national level national security, spiritual well-being, social life and cultural heritage are considered very important in bringing happiness, and that material wealth is considered less important for happiness. At the individual level the same importance is given to these elements, except for national security.

In general, our findings show that most people personally feel 'happy' or 'very happy' with respect to their spiritual well-being, the natural environment, social life and cultural heritage. The levels of happiness relating to material well-being were found to be lower. In assessing 'gross national happiness' a large number of respondents label the level of national happiness as 'very happy' or 'happy' (92\%). When compared with information from cross-national studies, this is a high score for a country with a small GDP. Although the data provided here are not completely comparable with the data available in the various worldwide studies on happiness levels in nations, we can make the observation that Bhutan occupies a special position, as shown in Figure 5. We should clearly distinguish between individual and collective happiness here. The ambition of the government of Bhutan is clearly to follow the top straight line of development as shown in Figure 5 rather than the common V-shaped route.

This paper represents the first sociological study of the Bhutanese people's perceptions of the development philosophy, the strategy, and the capacity for implementation. It provides a snapshot view of the people's interpretation of the past achievements and the values that underpin the future direction they want to take. For decision makers, it throws important light on the level of popularity, understanding and support for the development policy and the concerns it raises. The main elements of the development strategy are fairly widely supported by the Bhutanese people. However, there are also reasons for concern. We observe a certain level of uncertainty. This is expressed in the high ranking of national security as an important aspect of national happiness. Furthermore, people seem to feel a lot of pres- 


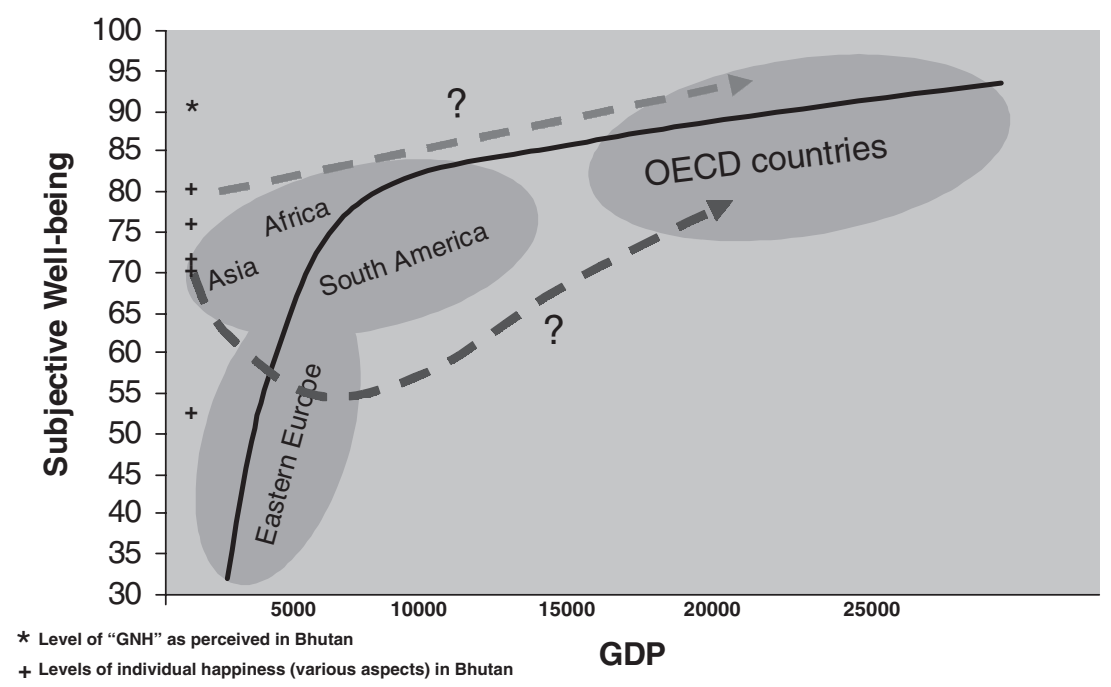

Figure 5. Subjective well-being by level of economic development

sure related to both conservation of the natural environment and preservation of culture. The risk of corruption is also clearly present in people's minds. This indicates that the present phase of development in the country is very fragile.

\section{References}

Asian Development Bank. 2005. Technical Assistance to the Kingdom of Bhutan for Capacity Building for the Bhutan Power Corporation. www.adb.org [27 September 2005].

Driessen PPJ, Glasbergen P. 2002. Paradigm shift in Dutch environmental politics. In Greening the Society, Driessen PPJ, Glasbergen P (eds). Kluwer: Dordrecht; 7-II.

Hirata J. 2003. Putting Gross National Happiness in the service of good development. The Journal for Bhutan Studies 9(4): 99-IOI.

Inglehart R, Klingemann H. 1996. Genes, Culture, Democracy, and Happiness: Subjective Well-Being Across Cultures. MIT Press: Cambridge, MA.

Mancall M. 2004. Bhutan's quadrilemma: to join or not to join the WTO, that is the question. The Journal for Bhutan Studies 9(5): $140-154$.

NEC. I998. The middle path. In National Environment Strategy for Bhutan. National Environment Secretariat: Thimphu; Ch. I, p. I7.

Payutto PA. 1988. Buddhist Economics - a Middle Way for the Market Place. http://www.geocities.com [I7 August 2005].

Phrabhavanaviriyakhun PD. 200I. Buddhist Economics http://www.urbandharma.org [I7 August 2005].

RGoB. I990. Environment and Sustainable Development, report on the Paro Workshop Bhutan. Thimphu: National Environment Secretariat-Q Reprographics.

RGoB. 1996. Eighth Five-Year Plan (1997-2002). Ministry of Planning-Keen: Bangkok, Thailand.

RGoB. I999. Bhutan 2020: a Vision for Peace, Prosperity and Happiness. Ministry of Planning-Keen: Bangkok, Thailand.

RGoB. 2002. Biodiversity Action Plan for Bhutan 2002. Ministry of Agriculture Nature Conservation Division-Keen: Bangkok, Thailand.

RGoB. 2003. Bhutan 2003: People at the Centre of Development. Ministry of Finance Department of Aid and Debt Management: Thimphu.

RGoB. 2005. Constitution of the Kingdom of Bhutan, draft as of 26 March 2005. Constitution Drafting Committee. www. bhutabstudies.org.bt [4 April 2005].

Schumacher EF. I966. Buddhist economics. In Asia Handbook, Wint G (ed.). Blond: London; 8. 
Sharrock G. 1999. Gross National Happiness: can environmental economics offer a way forward. In Gross National Happiness, Kinga $\mathrm{S}$ et al. (eds). Centre for Bhutan Studies: Thimphu.

Stehlik V. 1999. Gross National Happiness: a respite from a biblical economy or attaining utopia? In Gross National Happiness, Kinga S et al. (eds). Centre for Bhutan Studies: Thimphu; 52-58.

Tashi KP. 2004. The role of Buddhism in achieving Gross National Happiness. Paper read at Proceedings of the First International Seminar on Operationalisation of Gross National Happiness, Thimphu; 52-58.

Tashi KP, Prakke P, Chetri S. 1999. Gross National Happiness: concepts for the debate. In Operationalising Gross National Happiness, Kinga $\mathrm{S}$ et al. (eds). Centre for Bhutan Studies: Thimphu; IO4-II5.

Thinley J. I999. Values and development ‘Gross National Happiness’. In Gross National Happiness, Kinga S et al. (eds). Centre for Bhutan Studies: Thimphu.

Ura K (ed.). 2004. Deities, Archers and Planners in the Era of Decentralisation. Karma Ura: Thimphu.

van Vuuren DP, Smeets EMW. 2000. Ecological footprints of Benin, Bhutan, Costa Rica and the Netherlands. Ecological Economics 34(234): II5-I30.

Veenhoven R. I999. Quality of-life in individualistic society. A comparison of 43 nations in the early I990's. Social Indicators Research 48: I57-I86.

Welford R. 2000. Towards sustainable development - a Buddhist path. In Corporate Environmental Management Towards Sustainable Development, Welford R (ed.). Earthscan: London; Ch. 6.

Wickramasinge JW. 2000. People friendly economic development - an introduction to Buddhist theory of development economics. In Buddhist Economics, University of Sri Jayewardenepura, Dharmavijaya Foundation, Bauddhaloka Mawatha: Colombo; 39. 